\title{
Altitude and Ecological Distribution of Genus Litsea (Lauraceae) in Western Ghats of Karnataka, India
}

\author{
S.G. Srinivas and Y.L. Krishnamurthy* \\ Department of P.G Studies and Research in Applied Botany, Kuvempu University, Karnataka, India
}

Date Received: 12-04-2019

Date Accepted: 12-12-2019

\begin{abstract}
India is a subcontinent in the world with varied climatic regions, topographic variation results in the very diverse ecological diversity. Litsea is a largest genus in the family Lauraceae differentiated by its dioecious nature, distributed in tropical and subtropical regions which is influenced by some environmental factors. Present research work focussed on distribution of genus in the central Western Ghats of Karnataka, India. Litsea species were collected from 2013 to 2018 in different sampling sites. A total of 12 species were identified and reported from this region. The diversity indices of Litsea vary from species to species as well as region to region. L. floribunda is frequently distributed in all the study sites and it showed highest density when compared with other species, whereas, L. deccanensis distributed only in Sakaleshpur region and it showed lower diversity. The highest number of Litsea species occurred in Sakaleshpur region (10 species) and Mullayyanagiri region having only one species that is L. floribunda. The results indicate that Litsea distribution and diversity is rich in moderate rainfall regions of Western Ghats. The macro and micro nutrients of the soil in the study area reflects the distribution of the genus. There is a gradual increasing in tendency of the species richness with increasing elevation when compared with lower elevated regions. The genus also showed more sensitive and positive association with the elevation factor.
\end{abstract}

Keywords: Dioecious, elevation, nutrient, rainfall, soil

\section{Introduction}

The genus Litsea consists of about 400 species which is largest genus in the family Lauraceae differentiated by its dioecious nature, distributed in tropical and subtropical Asia, Australia, New Zealand, North America and subtropical South America (Chaing et. al., 2012). In India, about 45 species occur in evergreen and semi evergreen forests of Western Ghats of peninsular India and Eastern Himalayas. Among 45 species 18 species are endemic to south India (Bhuniya et al., 2010).

The genus Litsea shows higher distribution in North-Eastern states such as Meghalaya, Manipur, Assam, Arunachal Pradesh and Sikkim. In South India the species distributed in Tamil Nadu, Kerala, Karnataka, Maharashtra respectively. Twelve species of Litsea are reported in Karnataka (Saldanha, 1984). Most of the species distributed in Western Ghats areas, where only two species found in other than Western Ghats regions. Six species found in Andaman Nicobar Islands and only one species reported from Gujarat (Bhuniya et al., 2009).

Litsea trees are distributed in an altitude range of 600-2500 m, some of the endemic Litsea species grow particularly in some geographical regions, Litsea sikkimensis, L. oreophilla, restricted to Sikkim, $L$. membranifolia and L. mishmiensis confined to Arunachal Pradesh, L. travancorica only from Kerala, $L$. ghatica restricted to Western Ghats parts of Karnataka, Kerala and L. leiantha confined to Andaman and Nicobar Islands (Bhuniya and Mukherjee, 2012).

*Correspondence: murthy_ylk@yahoo.co.in

ISSN 2235-9370 Print/ISSN 2235-9362 Online @ University of Sri Jayewardenepura 108 
In India very limited research work has been done over the ecological diversity of Litsea (Saldanha, 1984; Bhuniya, 2009, 2010; Ganesan, 2011; Mishra and Naidu, 2013; Robi et al., 2015). In the world scenario, recently published taxonomic revisions published from Thailand with 35 species (Ngernsaengsaruay et al., 2011), Nepal with 11 species (Pendry et al., 2011) and in China with 74 species (Huang et al., 2008).

Biodiversity maintains some essential ecosystem functions (Brilliant et al., 2012). The immense biodiversity generates a variety of natural resources which helps in sustain the life of local communities. Understanding species diversity and distribution patterns is important for helping managers to evaluate the complexity and resources of these forests, trees from the major structural and functional basis of forest ecosystems and serve as indicators of changes at the landscape scale (Kumar et al., 2006).

Discussing and study the diversity of a particular genus or in group to get some idea about the genus and present status of genus leads to conservation. Field collection, base line data, generation of digital databases, monograph writing, exploration of genetic diversity and development of sacred forests with special reference to particular forest or genus, initiation of gene and seed banks, establishment of micro propagation lead to conservation of the species.

Different climatic and topographic gradient results in varied vegetation types, evergreen to semievergreen, moist deciduous to dry deciduous forest types, leads to diverse flora and fauna (Ramesh et al., 1997). The species diversity and distribution in the tropics varies dramatically from place to place because of some environmental, edaphic and topographic factors (Pitman et al., 2002). Present study focussed on influence of ecological factors and altitudinal factors on distribution of Litsea species in Central Western Ghats.

\section{Materials and Methods}

\subsection{Study area}

Study area of our research is Central Western Ghats of Karnataka. Western Ghats is the major biodiversity hot spot in India. Karnataka is situated at angle of Central Western Ghats. Karnataka is one of the major state in India that covers around 191,976 $\mathrm{km}^{2}$ and contribute 5.83 per cent of total geographical area of India. The state is situated in Deccan Plateau and bordered by the Arabian Sea to the West, Maharashtra to the North, Goa to the Northwest, Andhra Pradesh-Telangana to East, Kerala to the Southwest and Tamil Nadu to the Southeast. About 21 per cent of total geographical area of the state is covered by different forest types.

Western Ghats regions of Karnataka include seven districts, Shivamogga, Chikkamagaluru, Hassan, Kodagu, Udupi, Dakshina Kannada and Uttara Kannada districts. The major vegetation types include tropical evergreen forests, semi evergreen forests, deciduous forests, dry deciduous forests, scrubby forests, shola and savanna grasslands. Our preliminary survey revealed that the Litsea species are distributed in the evergreen and semi evergreen forests; hence we are restricting our survey to the forests of seven districts of Western Ghats. 


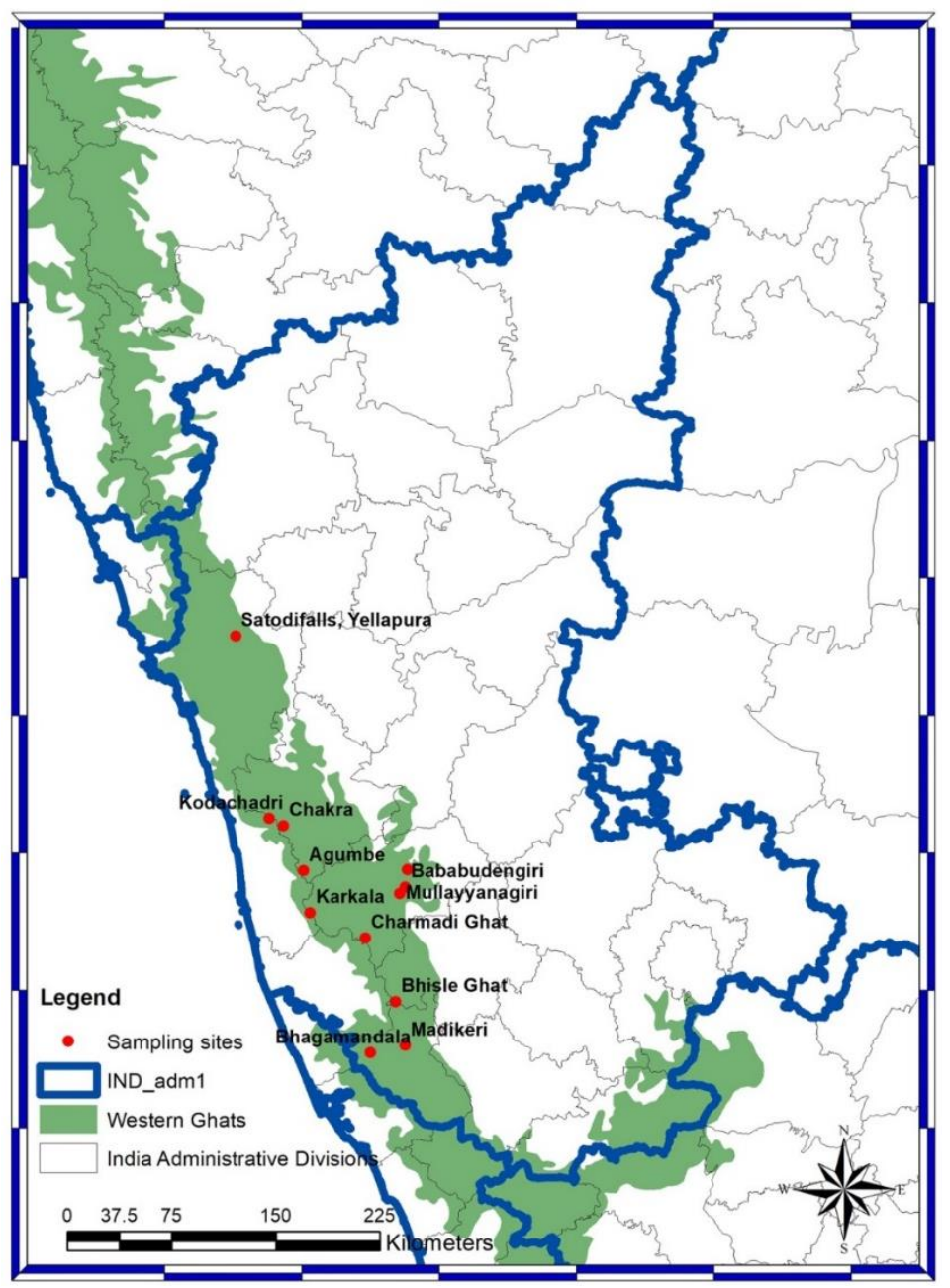

Figure 1. Map of the Central Western Ghats regions of Karnataka from where the samples were collected.

\subsection{Field survey and collection of Litsea species}

Field survey was conducted frequently in evergreen, semi evergreen and deciduous forests in Western Ghats of Karnataka in eight study sites, such as Kemmannugundi (KMD), Mullayyanagiri (MLG), Madikeri (MDK), Kodachadri (KDC), Agumbe (AGM), Karkala (KRK), Sakaleshpur (SKP) and Yellapur (YLP) region. Stratified random sampling method was used to collect the tree data. A standard size, $250 \times 4$ $\mathrm{m}$ belt transects were laid in each study area covering 3 transects in each study sites. In each study site available Litsea species were collected. Morphological characters were observed and noted among the different populations of Litsea genus.

The Litsea species collected were identified through standard floras (Gamble, 1998; Saldanha, 1996). This was supplemented with literature survey and study of herbarium specimens deposited at west region herbarium centre Pune, Botanical survey of India and herbarium JCB, Centre for Ecological Sciences (CES), Indian institute of Science Bengaluru. Digital images of type specimens were referred from the Royal botanical gardens, Kew London, UK to confirm the identity of the species. Herbarium specimens of all the collected species were deposited in herbarium JCB, Centre for Ecological Sciences, Indian institute of Science Bengaluru, India. All the important distinguishable taxonomic characters of each species were tabulated. Based on these important characters key for identification of the species were prepared. 


\subsection{Influence of ecological factors on distribution}

To study the influence of environmental factors on distribution of Litsea species like temperature, rain fall were recorded available in the field. Climatic data is also obtained from www.worldclimate.org website. Topographic factors like latitude, longitude and altitudes of sampling sites were noted by using hand held GPS (Garmin Etrex, USA). Temperature was recorded using digital thermometer. In each study site the data was used to correlate with species distribution.

The edaphic factors were studied by collecting the soil that occurs in all the study sites. Different types of soil like loamy soil, reddish to brown, clayey loam to lateritic soil, fertile red loamy soil samples were collected. In all the study sites soil samples were collected from a rooting depth of $15 \mathrm{~cm}$ at each site. Samples were air-dried, crushed using a pestle and mortar and then passed through a screen before analysis. Standard methodology was followed for estimating soil salinity, $\mathrm{pH}$, chemical nutrients of this collected soil samples tested in laboratory.

\subsection{Species distribution modelling map of Litsea}

More number of species were distributed in Western Ghats of South India. To know the Litsea species distribution throughout the Western Ghats predicted a species distribution map along the Western Ghats using climatic parameters by MaxEnt modelling method. The important climatic parameters such as annual mean temperature, annual rainfall, mean precipitation in different months across the year. Graphical Information System (GIS) and species mapping is an advanced tool for making species distribution models of different species of Litsea in Western Ghats of India. Species distribution range of each species topographic data of 12 species of Litsea in Karnataka across the eight study sites was used to generate the species distribution map along the Western Ghats of India.

\section{Results and Discussion}

\subsection{Diversity indices and ecology of genus Litsea}

A total of twelve species comprised Litsea bourdillonii, L. coriacea, L. deccanensis, L. floribunda, L. ghatica, L. glabrata, L. glutinosa, L. laevigata, L. mysorensis, L. oleoides, L. stocksii, L. wightiana were identified from our research study area (Table.1). Litsea floribunda, L. stocksii, L. wightiana, L. laevigata species were distributed abundantly when compared with other species. Litsea ghatica, L. coriaceae and $L$. deccanensis are rare species to Western Ghats of Karnataka.

Table 1: Name of all the species occur in Central Western Ghats of Karnataka.

\begin{tabular}{|c|l|c|c|}
\hline Sl. No. & Species name & Field collection number & Voucher deposition number \\
\hline 1 & Litsea bourdillonii & KUABL 1001 & HJCB-N-0282 \\
\hline 2 & Litsea coriacea & KUABL 1002 & HJCB-N-0283 \\
\hline 3 & Litsea deccanensis & KUABL 1003 & HJCB-N-0284 \\
\hline 4 & Litsea floribunda & KUABL 1004 & HJCB-N-0285 \\
\hline 5 & Litsea ghatica & KUABL 1005 & HJCB-N-0286 \\
\hline 6 & Litsea glabrata & KUABL 1006 & HJCB-N-0287 \\
\hline 7 & Litsea glutinosa & KUABL 1007 & HJCB-N-0288 \\
\hline 8 & Litsea laevigata & KUABL 1008 & HJCB-N-0289 \\
\hline 9 & Litsea mysorensis & KUABL 1009 & HJCB-N-0290 \\
\hline 10 & Litsea oleoides & KUABL 1010 & HJCB-N-0291 \\
\hline 11 & Litsea stocksii & KUABL 1011 & HJCB-N-0292 \\
\hline 12 & Litsea wightiana & KUABL 1012 & HJCB-N-0293 \\
\hline
\end{tabular}

The diversity indices of Litsea vary from species to species as well as region to region. All the twelve species of Litsea distributed in different locations. L. floribunda is frequently distributed in all the 
study sites and it showed highest density when compared with other species, whereas, Litsea deccanensis distributed only in Sakaleshpur region and it showed lower density. The highest individuals of Litsea species occurred in Sakaleshpur region (10 species) and Mullayyanagiri region having only one species that is Litsea floribunda.

Table 2: Diversity indices of genus Litsea in all the study sites of Western Ghats.

\begin{tabular}{|l|c|c|c|c|c|c|c|c|c|}
\hline $\begin{array}{l}\text { Study } \\
\text { sites }\end{array}$ & Frequency & $\begin{array}{c}\text { Den/ } \\
\text { Transect }\end{array}$ & Abundance & RF & RD & RA & IVI & $\begin{array}{c}\text { A/F } \\
\text { Ratio }\end{array}$ & $\begin{array}{c}\text { Basal area } \\
\mathrm{m}^{2} / \mathrm{ha}\end{array}$ \\
\hline KMD & 0.71 & 48.40 & 56.01 & 32.40 & 56.82 & 49.13 & 86.59 & 100.00 & 928.40 \\
\hline MLG & 1.00 & 47.67 & 47.67 & 10.00 & 50.00 & 44.90 & 60.00 & 4.77 & $1,904.79$ \\
\hline MDK & 1.00 & 41.66 & 41.66 & 37.52 & 74.86 & 68.14 & 112.38 & 4.45 & 910.08 \\
\hline KDC & 0.87 & 39.95 & 42.71 & 43.90 & 59.36 & 53.79 & 101.01 & 5.91 & 408.30 \\
\hline AGM & 0.66 & 37.00 & 48.00 & 70.16 & 35.55 & 53.63 & 45.07 & 87.16 & 176.34 \\
\hline KRK & 0.67 & 13.00 & 22.00 & 8.65 & 20.99 & 21.78 & 24.92 & 15.38 & 58.15 \\
\hline SKP & 0.53 & 22.70 & 42.00 & 6.48 & 41.97 & 42.77 & 43.68 & 28.06 & 112.80 \\
\hline YLP & 0.68 & 26.00 & 34.50 & 24.09 & 29.21 & 35.97 & 31.37 & 34.14 & 99.32 \\
\hline
\end{tabular}

Litsea is frequently distributed in all the study sites. Highest density was found in Kemmannugundi region (48.40) and lower in Karkala region (13.0). Kemmannugundi region showed higher abundance when compared with other study sites whereas, Madikeri, Kodachadri and Sakaleshpur region showed similar abundance values. Relative frequency was higher in Agumbe region and lower in Sakaleshpur region. The genus Litsea covers the more basal area in Mullayyanagiri $(1,904.79)$ and low in Karkala $(58.15)$ region (Table 2).

Apart from ecological parameters with edaphic factors, the role of other associated species is very prominent in the growth, development and evenness of a species. The dominant companion tree species are Laural members such as Cinnamomum, Neolitsea and Cryptocarya. Most of the species representing the family Lauraceae (12 species) due to the preference of favourable environmental factors in all the study sites. It is evident that Lauraceae is the dominant family of the companion species in the Jaintia hills in North East India (Upadhaya et al., 2003).

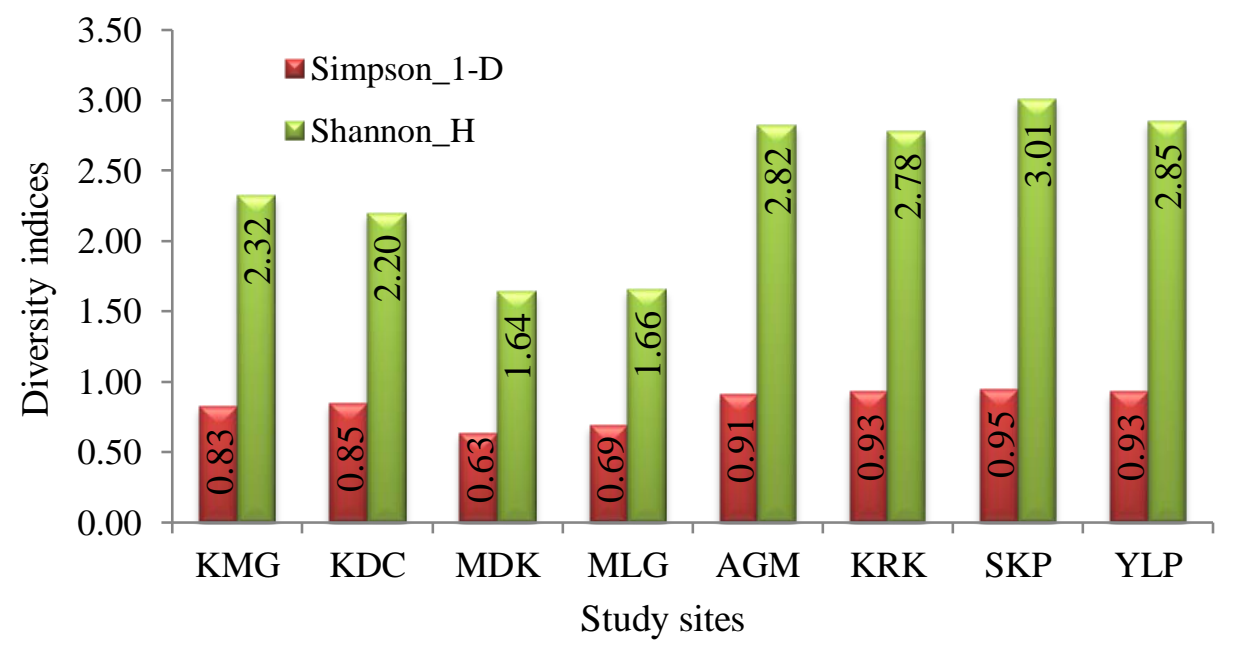

Figure 2. Shannon and Simpson diversity index in different study sites of Western Ghats of Karnataka. 
Among eight study sites of the Western Ghats, the diversity indices showed that the highest richness was observed in Mullayyanagiri with highest number of individuals. It is revealed that the highest Simpson and Shannon indices observed in Sakaleshpur $(\mathrm{D}=0.95$ and $\mathrm{H}=3.01)$, Yellapur $(\mathrm{D}=0.93$ and $\mathrm{H}=2.85$ ), Karkala ( $\mathrm{D}=0.93$ and $\mathrm{H}=2.78)$, Agumbe $(\mathrm{D}=0.91$ and $\mathrm{H}=2.82)$, Kodachadri $(\mathrm{D}=0.84$ and $\mathrm{H}=2.19)$, Kemmannugundi $(\mathrm{D}=0.82$ and $\mathrm{H}=2.32)$, Mullayyanagiri $(\mathrm{D}=0.69$ and $\mathrm{H}=1.65)$ and Madikeri $(\mathrm{D}=0.63$ and $\mathrm{H}=1.64$ ) (Figure 2).

In the present study, a total of twelve species were encountered in all the study sites of central Western Ghats of Karnataka. Whereas, in previous studies sixteen species reported from Western Ghats of Southern India (Rao, 2012), twenty species occurred including new species L. udayanii (Robi and Udayan, 2014), nine species reported from Terai region of West Bengal (Choudhury et al., 2014), twenty two species from Eastern Himalaya region, seventeen species from North Eastern part and only six species from Andaman and Nicobar region of India (Bhuniya et al., 2009). The data showed that, the present results with previous studies of other regions, the central Western Ghats of Karnataka has more endemic species and present study reports that Litsea ghatica is a rare species from Karnataka region and particularly endemic to Western Ghats of Karnataka. This species were observed from Kodachadri and Sakaleshpur regions.

\subsection{Influence of climatic factors on diversity and distribution of Litsea (a) Rainfall}

Species diversity and distribution in the tropics varies from one area to other area because of some environmental, edaphic and topographic factors (Rodrigues et al., 2018). Rainfall is an important climatic factor for the growth, development and distribution of plants. In the present study, five years rainfall data from 2012 to 2016 has been used for the statistical analysis. According to the rainfall data, year 2013 had received highest average rainfall $(259.18 \mathrm{~mm})$ when compared with other years in all districts. It is followed by $2014(237.40 \mathrm{~mm}), 2012(200.60 \mathrm{~mm}), 2015(190.61 \mathrm{~mm})$ and $2016(161.17 \mathrm{~mm})$ (Figure 3).

Among seven districts, Udupi received highest rainfall $(344.71 \mathrm{~mm})$ when compared to other districts, while lowest rainfall recorded in Hassan district $(71.36 \mathrm{~mm})$. Overall rainfall data revealed that, Udupi received highest average rainfall in the year 2013 as $404.38 \mathrm{~mm}$ and lowest average rainfall recorded in Hassan in the year 2016 (48.36 mm). During 12 months, three months such as June, July and August month received high average rainfall in descending order.

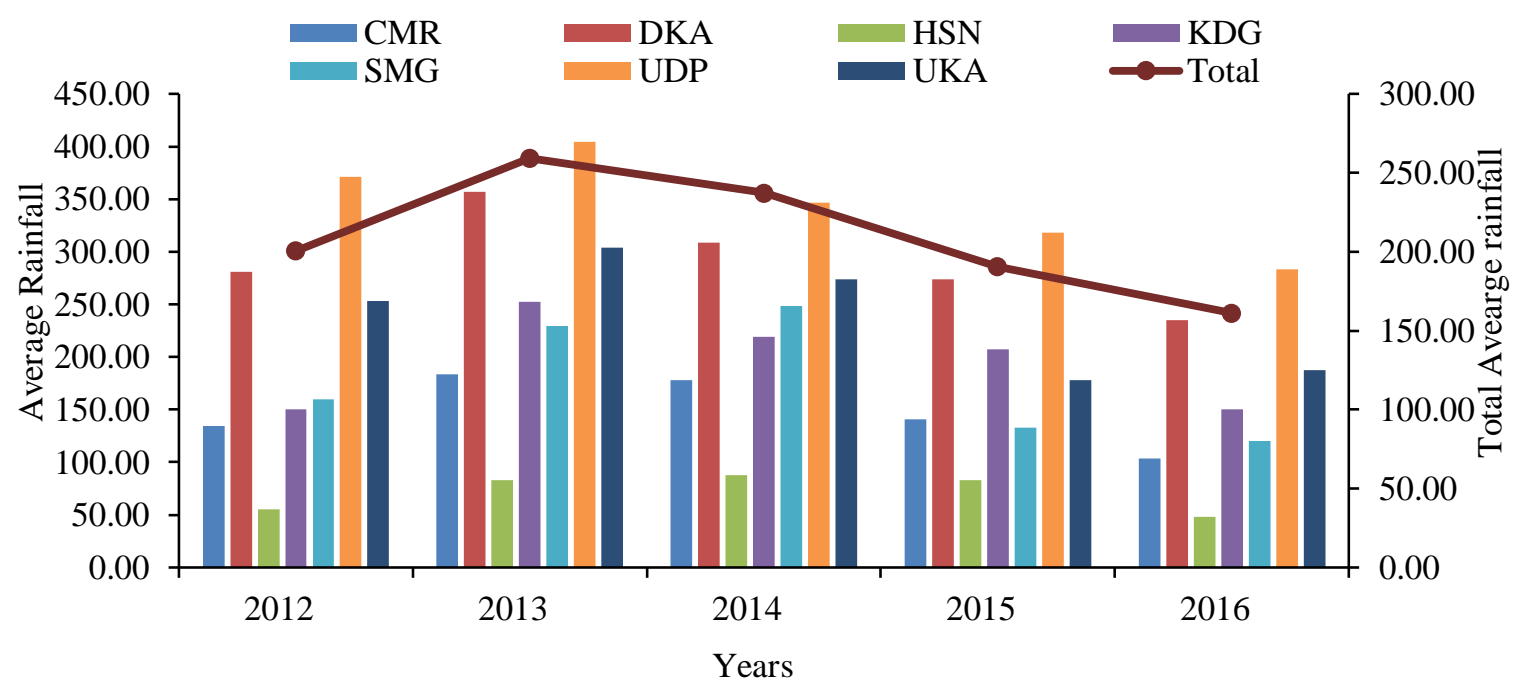

Figure 3. Year-wise average rainfall data of seven districts from 2012 to 2016. 
Average rainfall data showed that Udupi district received highest rainfall followed by Dakshina Kannada, Uttara Kannada, Shivamogga, Kodagu, Chikkamagaluru and Haasan district receive lower rainfall because the only Sakaleshpur region comes under the Western Ghats part of Karnataka. The density of genus Litsea is higher in Mullayyanagiri region (48.40), followed by Kemmannugundi (47.67), Madikeri (41.66), Kodachadri (39.95), Agumbe (37.0), Karkala (13.0), Sakaleshpur (22.70), Yellapur (26.0) (Table. $2)$. The results indicate that Litsea distribution and diversity rich in moderate rainfall regions of Mullayyanagiri and Kemmannugundi regions of Chikkamagaluru district, Madikeri of Kodagu district and Kodachadri, Agumbe of Shivamogga district. The average temperature of the study sites was $27^{\circ} \mathrm{C}$. The temperature in the study sites reflect on the flowering of genus Litsea. In low temperature and high humidity conditions, flowering occurs on Litsea trees and flowers blooms in the cold conditions.

\section{(b) Nutrient contents in soil}

Results of soil analysis of different study sites indicated Kemmannugundi soil has more pH value (6.00) than Madikeri (5.8), Mullayyanagiri, Yellapur (5.6) and least pH documented in Agumbe soil (5.2). As per electrical conductivity analysis, Kemmannugundi soil showed more EC (0.29), it is followed by Sakaleshpur (0.26), Karkala (0.23), Mullayyanagiri (0.19), Yellapur (0.15), Agumbe (0.12), Madikeri (0.1) and Kodacahdri (0.07) (Table. 3).

In macro nutrients, high amount of Phosphorus was found in two sites Kemmannugundi and Mullayyanagiri (12.9) and it followed by Karkala (12.6) and lower amount of Phosphorus was found in Madikeri soil. High amount of Potassium was recorded in Agumbe (101.26 ppm) and least in Kemmannugundi soil. Second nutrient Sulphur was also recorded high amount in Agumbe soil (19.5 ppm) and it followed by Kemmannugundi (16 ppm), Mullayyanagiri and Madikeri (14.25 ppm), Sakaleshpur (13.9 ppm), Yellapur (10 ppm), Karkala (7.2 ppm) and Kodachadri (0.3 ppm). Available micro nutrients such as Zinc, Copper, Manganese, Iron and Boron in different study sites sample showed much variability in their values. The high amount of Zinc was recorded in Karkala soil (2.84 ppm) and least in Kodacahdri soil (2.04 ppm). The high amount of Copper and Boron was found in Madikeri soil (0.95 ppm and $4.49 \mathrm{ppm}$ respectively) and low in Karkala soil $(\mathrm{Cu}=0.14 \mathrm{ppm})$ and Yellapur soil $(\mathrm{B}=0.03 \mathrm{ppm})$ respectively. The high Amount of Manganese and Iron was found in Yellapur soil, 73.26 ppm and 111.4 ppm, respectively (Table. 3).

Table 3: Nutrient characteristics of soil collected from study sites of Western Ghats, Karnataka.

\begin{tabular}{|l|c|c|c|c|c|c|c|c|c|c|}
\hline $\begin{array}{l}\text { Sample } \\
\text { sites }\end{array}$ & $\mathrm{pH}$ & $\begin{array}{c}\mathrm{EC} \\
(\mu \mathrm{mhos} / \\
\mathrm{cm})\end{array}$ & $\begin{array}{c}\mathrm{P} \\
(\mathrm{Kg} / \mathrm{ac})\end{array}$ & $\begin{array}{c}\mathrm{K} \\
(\mathrm{ppm})\end{array}$ & $\begin{array}{c}\mathrm{S} \\
(\mathrm{ppm})\end{array}$ & $\begin{array}{c}\mathrm{Zn} \\
(\mathrm{ppm})\end{array}$ & $\begin{array}{c}\mathrm{Cu} \\
(\mathrm{ppm})\end{array}$ & $\begin{array}{c}\mathrm{Mn} \\
(\mathrm{ppm})\end{array}$ & $\begin{array}{c}\mathrm{Fe} \\
(\mathrm{ppm})\end{array}$ & $\begin{array}{c}\mathrm{B} \\
(\mathrm{ppm})\end{array}$ \\
\hline KMD & 6.0 & 0.29 & 12.9 & 54.35 & 16.00 & 2.54 & 0.17 & 52.40 & 49.28 & 2.11 \\
\hline MLG & 5.6 & 0.19 & 12.9 & 84.44 & 14.25 & 2.46 & 0.26 & 3.26 & 69.28 & 0.55 \\
\hline KDC & 5.3 & 0.07 & 11.5 & 58.15 & 0.30 & 2.04 & 0.71 & 16.14 & 58.71 & 2.66 \\
\hline MDK & 5.8 & 0.10 & 5.3 & 88.80 & 14.25 & 2.49 & 0.95 & 48.48 & 82.14 & 4.49 \\
\hline AGM & 5.2 & 0.12 & 7.2 & 101.26 & 19.50 & 2.66 & 0.17 & 8.47 & 78.52 & 3.95 \\
\hline KRK & 5.3 & 0.23 & 12.6 & 60.30 & 7.20 & 2.84 & 0.14 & 26.20 & 64.15 & 3.72 \\
\hline SKP & 5.5 & 0.26 & 10.6 & 72.40 & 13.90 & 2.75 & 0.81 & 32.30 & 69.80 & 4.26 \\
\hline YLP & 5.6 & 0.15 & 7.2 & 75.53 & 10.00 & 2.26 & 0.35 & 73.26 & 111.4 & 0.03 \\
\hline
\end{tabular}

Soil $\mathrm{pH}$ ranged from 5.2 to 6.0 in the sampling sites which is a slightly acidic $\mathrm{pH}$, in Kemmannugundi the $\mathrm{pH}$ is near to neutral (6.0) due to salt washed from other areas getting deposited. The 
electrical conductivity ranged from 0.07-0.29, micro and macro nutrients are slightly varied from different study sites. Soil analysis data indicates that Litsea abundance is higher in 5.6 to $6.0 \mathrm{pH}$ regions (Kemmannugundi, Madikeri, Mullayyanagiri). The macro and micro nutrients of the soil in the study area reflects the distribution of the genus, according to edaphic data, Litsea tree prefers high iron content in soil. Soil $\mathrm{pH}$, organic matter clearly reflects on the diversity and distribution of tress. The Litsea tree species are found distributed in valley areas of Western Ghats. These valleys are rich in all micro and macro nutrients, density of tree species are higher where nutrients are higher in soil.

\section{(c) Topographic factors}

Topographic factors are more important in distribution of Lauraceae species including genus Litsea. The study site Mullayyanagiri is the highest elevation region $(1,619 \mathrm{~m})$ in south India followed by Kemmannugundi (1,536 m), Kodachadri (1,199 m), Madikeri (1143 m) and least in Karkala (639 m) (Table. 4). In the present study, the diversity data correlated with altitudinal data. The species showed higher rate of distribution in elevated altitudinal regions when compare to lower altitudes. The density of Litsea trees is higher in Mullayyanagiri, Kemmannugundi, Kodachadri and Madikeri when compare to other study sites. It is evident from the results; species prefers high altitudinal habitats from sea level it distributed around $601 \mathrm{~m}$ to $1,619 \mathrm{~m}$ elevation. There is a gradual increasing in tendency of the species with increasing elevation when compare with lower elevated regions. This is because of the higher atmospheric moisture and lower temperature in high altitudinal habitats. Most of the Laural members distributed in higher altitudinal regions along with genus Litsea. The abundance, frequency ratio indicated that the Litsea showed clumped or contagious distribution pattern and seedlings are adopted to grow close to the mother trees.

In previous studies confirmed that the topographic factors are important in woody tree species distribution when compare to other environmental parameters. Species distribution and forest compositions were strongly associated to topographic parameters reported in mountain forests of China (Zhang et al., 2016). This study was also reported that the elevation is the important factor positively affects the tree species distribution, in present study the tree species Litsea also showed more sensitive and positive association with the elevation factor.

Table 4: Topographic data of different sampling sites of Litsea in Western Ghats, Karnataka.

\begin{tabular}{|l|l|c|c|c|}
\hline Sampling sites & District & Latitude & Longitude & Altitude (m) \\
\hline Kemmannugundi & Chikkamagaluru & $13^{\circ} 32^{\prime} 25^{\prime \prime} \mathrm{N}$ & $75^{\circ} 45^{\prime} 55^{\prime \prime} \mathrm{E}$ & 1,536 \\
\hline Mullayyanagiri & Chikkamagaluru & $13^{\circ} 23^{\prime} 25^{\prime \prime} \mathrm{N}$ & $75^{\circ} 42^{\prime} 59^{\prime \prime} \mathrm{E}$ & 1,619 \\
\hline Kodachadri & Shivamogga & $13^{\circ} 51^{\prime} 32^{\prime \prime} \mathrm{N}$ & $74^{\circ} 52^{\prime} 20^{\prime \prime} \mathrm{E}$ & 1,199 \\
\hline Agumbe & Shivamogga & $13^{\circ} 31^{\prime} 56^{\prime \prime} \mathrm{N}$ & $75^{\circ} 05^{\prime} 38^{\prime \prime} \mathrm{E}$ & 664 \\
\hline Chakra & Shivamogga & $13^{\circ} 48^{\prime} 52^{\prime \prime} \mathrm{N}$ & $74^{\circ} 57^{\prime} 55^{\prime \prime} \mathrm{E}$ & 601 \\
\hline Bhagamandala & Kodagu & $12^{\circ} 22^{\prime} 84^{\prime \prime} \mathrm{N}$ & $75^{\circ} 31^{\prime} 32^{\prime \prime} \mathrm{E}$ & 952 \\
\hline Madikeri & Kodagu & $12^{\circ} 25^{\prime} 69^{\prime \prime} \mathrm{N}$ & $75^{\circ} 44^{\prime} 61^{\prime \prime} \mathrm{E}$ & 1,143 \\
\hline Bhisle Ghat & Hassan & $12^{\circ} 42^{\prime} 42^{\prime \prime} \mathrm{N}$ & $75^{\circ} 41^{\prime} 17^{\prime \prime} \mathrm{E}$ & 752 \\
\hline Satodi falls, Yellapur & Uttara Kannada & $14^{\circ} 59^{\prime} 58^{\prime \prime} \mathrm{N}$ & $74^{\circ} 38^{\prime} 87^{\prime \prime} \mathrm{E}$ & 734 \\
\hline Charmadi Ghat & Dakshina & $13^{\circ} 06^{\prime} 44^{\prime \prime} \mathrm{N}$ & $75^{\circ} 29^{\prime} 37^{\prime \prime} \mathrm{E}$ & 808 \\
\hline Karkala & Udupi & $13^{\circ} 16^{\prime} 11^{\prime \prime} \mathrm{N}$ & $75^{\circ} 08^{\prime} 09^{\prime \prime} \mathrm{E}$ & 639 \\
\hline
\end{tabular}




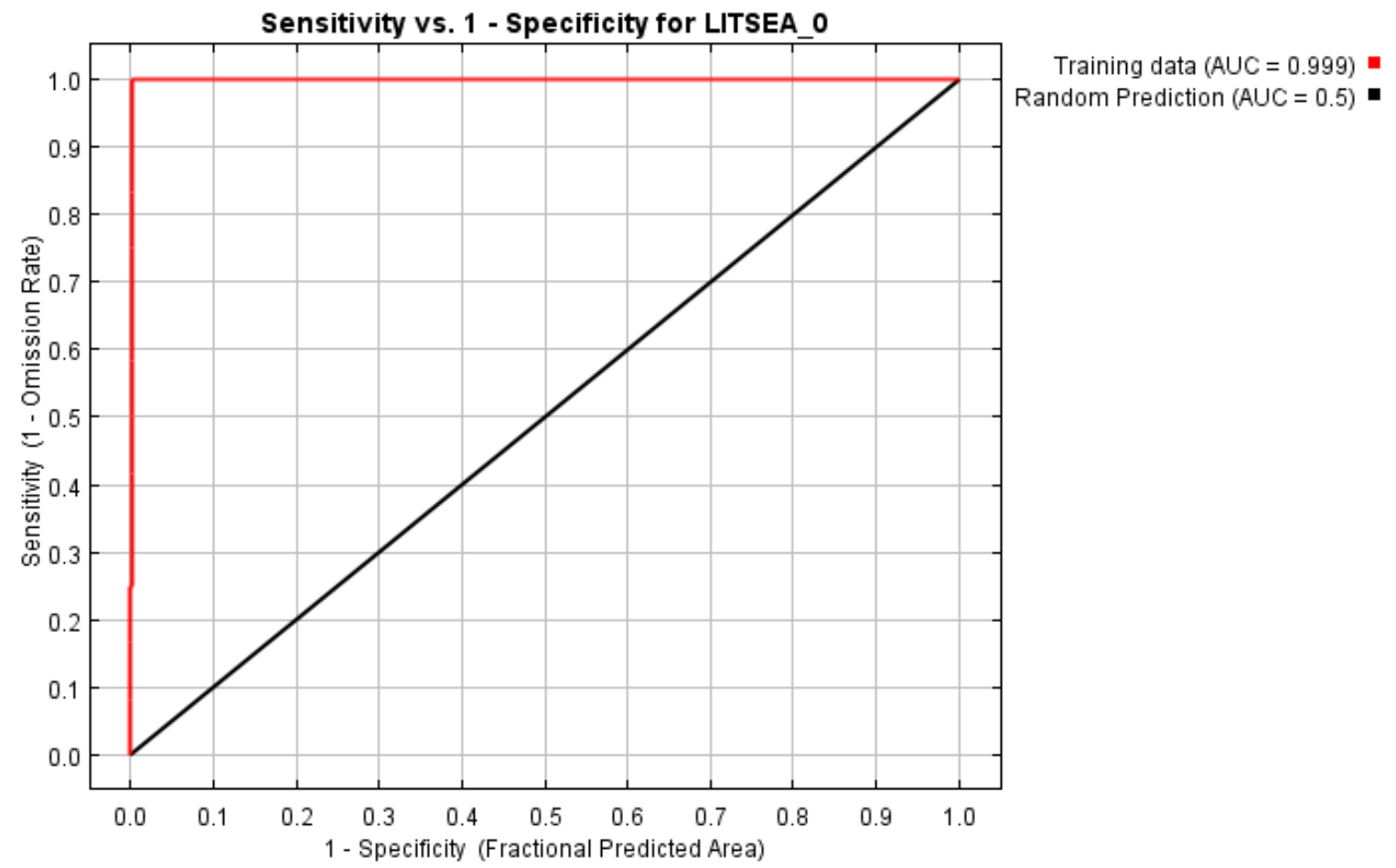

Figure 4. Receiver operating characteristics for Litsea.

The graph obtained by software was Receiver Operating Characteristic curve for the similar data. This graph defines the specificity using predicted area than true commission. It indicates the maximum achievable Area Under Cover (AUC) is less than one (AUC=0.999) (Figure 4). The AUC value of training data almost nearer to one, hence this species distribution model consider as good SDM model and this implies Litsea species has 99 per cent chance of complete distribution in a place of Western Ghats.

Present study shows distribution of Litsea similar to the species distribution model results in Central Western Ghats of Karnataka. The distribution of the trees was higher in high SDM value regions and these areas appear darken red colour, medium species areas appear yellow colour and in blue colour regions there is no reports of Litsea distribution (Figure 5). Distribution showed in Kemmannugundi, Mullayyanagiri, Kodachadri, Agumbe, Madikeri areas of Central Western Ghats are higher SDM values and appears in dark red region. Sakaleshpur, Charmadi Ghat, Yellapur, Kavaledurga, Hosanagara, Karkala regions showed medium distribution of Litsea and these areas having medium SDM values and appears in yellow coloured regions in the distribution model.

Litsea trees distribution predicted across the Western Ghats of South India. In Maharashtra region of Western Ghats having deciduous forests, Mahabaleshwar, Satara regions showed medium species distribution pattern. Castle rock and Kulem regions of Goa is a rich biodiversity area and covers mountains and valleys showed higher distribution of Litsea. Tamil Nadu region of Western Ghats includes evergreen forests of Kalakkad Mundanthurai Tiger Reserve (KMTR) of Tirunelveli and Mudumalai reserve forests around Ooty, Coimbatore and Nilgiris region having higher number of Litsea species which showed rich distribution of species. Kerala parts Western Ghat regions show rich biodiversity when compare to other regions. Highest number of Litsea species will be found in Kerala by previous records including more number of endemic species. These species are distributed in Periar National park region, Kannur, Idukki, 
Thekkady, Munnar and Wayanad regions. From the distribution model analysis, these Western Ghat areas are higher SDM values and most of Litsea species distributed in this region.

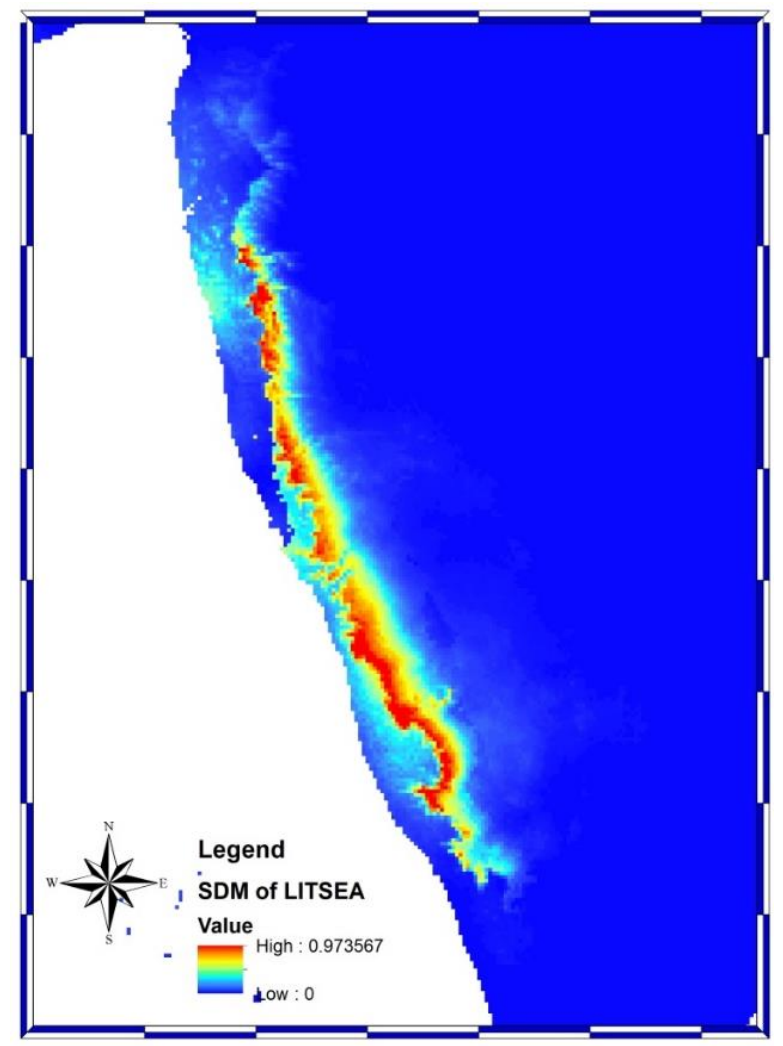

Figure 5. Species distribution model (SDM) of Litsea in Western Ghats of India.

\section{Conclusion}

In present study a total of twelve species (Litsea bourdillonii, L. coriacea, L. deccanensis, $L$. floribunda, L. ghatica, L. glabrata, L. glutinosa, L. laevigata, L. mysorensis, L. oleoides, L. stocksii and L. wightiana) were found and identified from our study area. The diversity and ecological data indicated that it is varied from one region to another region by the influence of external factors.

The environmental factors such as rainfall, temperature and edaphic factors such as soil and higher elevation influence the distribution of Litsea. The analysed rain fall data indicate that trees distribution and diversity is rich in moderate rain fall regions of Mullayyanagiri and Kemmannugundi regions of Chikkamagaluru district, Madikeri of Kodagu district and Kodachadri, Agumbe of Shivamogga district. The temperature in the study sites reflects on flowering of the genus. In Low temperature and high humidity condition the flowering event occurs on the trees. Soil data indicates that Litsea diversity and distribution is higher in 5.6 to $6.0 \mathrm{pH}$ regions (Kemmannugundi, Madikeri, Mullayyanagiri). The macro and micro nutrients of the soil in the study area reflects the distribution of the genus. The tree species are found distributed in valley areas of Western Ghats. These valleys are rich in all micro and macro nutrients. Tree density is higher where nutrients are higher in soil.

In present study, correlation of the diversity data with altitudinal data, the species showed higher distribution in elevated altitudinal regions when compared with lower altitudes. There is a gradual increase in tendency of the species with increasing elevation when compared with lower elevated regions. This is because of the higher atmospheric moisture and lower temperature in high altitudinal habitats. Most of the 
Laural members distributed in higher altitudinal regions along with genus Litsea. This study was also reported that the elevation is the important factor positively affects the tree species distribution.

\section{Acknowledgments}

Authors are thankful to Department of Science and Technology (DST), New Delhi, for providing INSPIRE fellowship (IF140097) to Srinivas S.G, which provided financial support for the study. The authors also acknowledges to Kuvempu University and Applied Botany department for providing infrastructural and administrative support. Specially authors acknowledge the Karnataka forest department for according permission to enter the forests.

\section{References}

Bhuniya, T. and Mukherjee, S.K., 2012. Status of Litsea Lam. (Lauraceae) in Andaman and Nicobar islands, India. Systematics of Flowering Plants, 2012:145-148.

Bhuniya, T., Singh, P. and Mukherjee, S.K., 2009. Distribution of the genus Litsea Lam. (Lauraceae) in India with special reference to rare and endemic species. Phytotaxonomy, 9:116-121.

Bhuniya, T., Singh, P. and Mukherjee, S.K., 2010. An account of the species of Litsea Lam. (Lauraceae) endemic to India. Bangladesh Journal of Plant Taxon, 17:183-191.

Brilliant, R., Varghese, V.M., Paul, J. and Pradeep Kumar, A.P., 2012. Vegetation analysis of montane forest of Western Ghats with special emphasis on RET species. International journal of Biodiversity and Conservation, 4:652-664.

Chiang, Y.C., Shih, H.C., Huang, M.C., Ju, L.P. and Hung, K.H., 2012. Characterization of microsatellite Loci from Litsea hypophaea (Lauraceae), a tree endemic to Taiwan. American Journal of Botany, 2012:251-254.

Choudhury, D., Biswas, R., Mandal, P. and Das, A.P., 2014. Diversity of Litsea Lamarck. (Lauraceae) in Terai and Duars regions of West Bengal, India. Pleione, 8:68-78.

Ganesan, R., 2011. Litsea kakkachensis (Lauraceae)-A new species from Agasthyamalai, Western Ghats, India. Rheedea, 21: 43-146.

Huang, P., Li, J. Li, X. and Van der Werff, H., 2008. Litsea. Flora of China, 7:118-141.

Kumar, A., Marcot, B.G. and Saxena, A., 2006. Tree species diversity and distribution patterns in tropical forests of Garo hills. Current Science, 91:1370-1381.

Mishra, C.K. and Naidu, G.R., 2013. Conservation of Litsea deccanensis: An NTFP under local extirpation. Indian Forester, 139:769-772.

Ngernsaengsaruay, C., Middleton, D.J. and Chayamarit, K., 2011. A revision of the genus Litsea Lam. (Lauraceae) in Thailand. Thai Forest Bulletin (Botany), 39:40-119.

Pendry, C.A., Watson, M.F., Akiyama, S., Ikeda, H., Rajbhandari, K.R. and Shrestha, K.K., 2011. Lauraceae. Flora of Nepal, 3:21-48.

Ramesh, B.R. and Pascal, J.P., 1997. Atlas of the endemics of the Western Ghats (India): Distribution of tree species in the evergreen and semi evergreen forests. Institute of Francais de Pondicherry, Publication du department d ecologie, 38:403.

Rao, R.R., 2012. Floristic diversity in Western Ghats: Documentation, conservation and bio prospection-A priority agenda for action. http://wgbis.ces.iisc.e639rnet.in/biodiversity/sahyadri_enews/newsle tter/ issue.

Robi, A.J., George, S. and Thushar, K.V., 2015. Litsea udayanii (Lauraceae): A new species from the southern Western Ghats, India. Phytotaxa, 222:44-50.

Robi, A.J. and Udayan, P.S., 2014. A taxonomic revision of the family Lauraceae from south India. Ph.D. Thesis, Kannur University, Kerala. 
Srinivas and Krishnamurthy /Journal of Tropical Forestry and Environment Vol. 9, No. 02 (2019) 108-119

Rodrigues, P., Schaefer, R., Silva, O., Junior, F., Santos, M. and Neri, V., 2018. The influence of soil on vegetation structure and plant diversity in different tropical savannic and forest habitats. Journal of Plant Ecology, 11:226-236.

Saldanha, C.J., 1984. Flora of Karnataka. Vol. 1, Oxford and IBH Publishing Ltd., New Delhi.

Upadhaya, K., Pandey, H.N., Law, P.S. and Tripathi, R.S., 2003. Tree diversity in sacred grooves of the Jaintia hills in Meghalaya, Northeast India. Biodiversity and Conservations, 12:583-597.

Zhang, C., Li, X., Chen, L., Xie, G., Liu, C. and Pei, S., 2016. Effects of topographical and edaphic factors on tree community structure and diversity of subtropical mountain forests in the lower Lancang river basin. Forests, 7:1-17. 